\title{
Pancreatic islet beta cell-specific deletion of G6pc2 reduces fasting blood glucose
}

\author{
Karin J Bosma1, Mohsin Rahim², Kritika Singh³, Slavina B Goleva3, Martha L Wall2, Jing Xia4, Kristen E Syring1, \\ James K Oeser ${ }^{1}$, Greg Poffenberger ${ }^{3}$, Owen P McGuinness ${ }^{1}$, Anna L Means ${ }^{5}$, Alvin C Powers ${ }^{1,3,6}$, Wen-hong Li \\ Lea K Davis ${ }^{1,3}$, Jamey D Young² and Richard M O'Brien'
}

1Department of Molecular Physiology and Biophysics, Vanderbilt University School of Medicine, Nashville, Tennessee, USA 2Department of Chemical and Biomolecular Engineering, Vanderbilt University School of Medicine, Nashville, Tennessee, USA ${ }^{3}$ Department of Medicine, Vanderbilt University School of Medicine, Nashville, Tennessee, USA ${ }^{4}$ Departments of Cell Biology and of Biochemistry, University of Texas Southwestern Medical Center, Dallas, Texas, USA 5Department of Surgery, Vanderbilt University School of Medicine, Nashville, Tennessee, USA ${ }^{6} V A$ Tennessee Valley Healthcare System, Nashville, Tennessee, USA

Correspondence should be addressed to R M O'Brien: richard.obrien@vanderbilt.edu

\begin{abstract}
The G6PC1, G6PC2 and G6PC3 genes encode distinct glucose-6-phosphatase catalytic subunit (G6PC) isoforms. In mice, germline deletion of G6pc2 lowers fasting blood glucose (FBG) without affecting fasting plasma insulin (FPI) while, in isolated islets, glucose-6phosphatase activity and glucose cycling are abolished and glucose-stimulated insulin secretion (GSIS) is enhanced at submaximal but not high glucose. These observations are all consistent with a model in which G6PC2 regulates the sensitivity of GSIS to glucose by opposing the action of glucokinase. G6PC2 is highly expressed in human and mouse islet beta cells however, various studies have shown trace G6PC2 expression in multiple tissues raising the possibility that G6PC2 also affects FBG through non-islet cell actions. Using real-time PCR we show here that expression of G6pc1 and/or G6pc3 are much greater than $G 6 p c 2$ in peripheral tissues, whereas G6pc2 expression is much higher than G6pc3 in both pancreas and islets with G6pc1 expression not detected. In adult mice, beta cell-specific deletion of G6pc2 was sufficient to reduce FBG without changing FPI. In addition, electronic health record-derived phenotype analyses showed no association between G6PC2 expression and phenotypes clearly unrelated to islet function in humans. Finally, we show that germline G6pc2 deletion enhances glycolysis in mouse islets and that glucose cycling can also be detected in human islets. These observations are all consistent with a mechanism by which G6PC2 action in islets is sufficient to regulate the sensitivity of GSIS to glucose and hence influence FBG without affecting FPI.
\end{abstract}

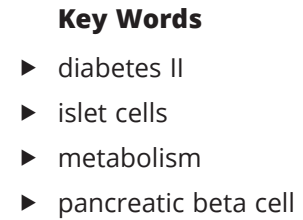

Journal of Molecular Endocrinology (2020) 64, 235-248

\section{Introduction}

Glucose-6-phosphatase catalyzes the hydrolysis of glucose-6-phosphate (G6P) to glucose and inorganic phosphate and is located in the endoplasmic reticulum (ER) membrane (Hutton \& O'Brien 2009). It is thought to exist as a multi-component enzyme system in which a
G6P transporter, encoded by the SLC37A4 gene, delivers substrate from the cytosol to the active site of a glucose6-phosphatase catalytic subunit (G6PC) in the lumen of the ER with transporters for inorganic phosphate and glucose returning the reaction products back to the 
cytosol (Hutton \& O'Brien 2009). The G6PC gene family is comprised of three members, G6PC1, G6PC2 and G6PC3 (Hutton \& O'Brien 2009). G6PC1, also known as G6PC or G6Pase, is predominantly expressed in liver and kidney where it catalyzes the terminal step in the gluconeogenic and glycogenolytic pathways (Hutton \& O'Brien 2009). G6PC3 is widely expressed, with especially high expression in kidney, testis, skeletal muscle and brain (Hutton \& O'Brien 2009). While G6PC3 catalyzes G6P hydrolysis in vitro (Shieh et al. 2003), its key substrate in vivo is thought to be the G6P analog 1,5-anhydroglucitol-6-phosphate (Veiga-da-Cunha et al. 2019). Based on Northern blotting and immunohistochemistry, G6PC2, also known as $I G R P$, was thought to be only expressed in pancreatic islets in mice (Arden et al. 1999) and humans (Martin et al. 2001). However, human RNA-Seq data, available through the GTEx database, suggest very low expression of G6PC2 in other tissues, including liver, skeletal muscle, and hypothalamus, raising the possibility that G6PC2 is functionally important in non-islet tissues.

The beta cell glucose sensor, glucokinase, catalyzes the formation of G6P from glucose and was thought to be the key factor that determines the rate of beta cell glycolytic flux (Iynedjian 2009, Matschinsky \& Wilson 2019). This glycolytic rate determines the sensitivity of glucosestimulated insulin secretion (GSIS) to glucose and hence the influence of beta cells on fasting blood glucose (FBG) (Iynedjian 2009, Matschinsky \& Wilson 2019). However, in isolated germline G6pc2-knockout (KO) islets glucose6-phosphatase activity (Pound et al. 2013) and glucose cycling (Wall et al. 2015), calculated as the percentage of the G6P generated from glucose that is converted back to glucose, are abolished. This results in a leftward shift in the dose response curve for GSIS (Pound et al. 2013) such that under fasting conditions, insulin levels are the same in wild type (WT) and germline G6pc2 KO mice but FBG is reduced in KO mice (Wang et al. 2007, Pound et al. 2013). These data challenge the existing dogma and suggest a new paradigm in which a glucokinase/G6PC2 futile cycle, rather than glucokinase alone, determines the rate of beta cell glycolytic flux and hence the sensitivity of GSIS to glucose. Molecular studies have shown that the ' $\mathrm{A}$ ' allele of the rs560887 SNP in the G6PC2 gene reduces G6PC2 RNA splicing (Baerenwald et al. 2013) and hence expression of full-length G6PC2. Consistent with the new paradigm, genome wide association studies (GWAS) have linked the rs560887 ' $\mathrm{A}$ ' allele to reduced FBG (BouatiaNaji et al. 2008, Chen et al. 2008).

The experiments described here provide further support for this new model by showing that glucose cycling also exists in human islets and that germline deletion of G6pc2 enhances glycolysis in mouse islets. In addition, gene expression analyses, electronic health record-derived phenotype analyses, and studies in a novel mouse model in which G6pc2 is specifically deleted in beta cells all suggest that G6PC2 is not active in non-islet tissues, and instead imply that an islet-specific action of G6PC2 is sufficient to mediate the effect of G6PC2 on FBG.

\section{Materials and methods}

\section{Animal care}

The Vanderbilt University Medical Center Animal Care and Use Committee approved all protocols used. Mice were maintained on a standard rodent chow diet (calorie contributions: $28 \%$ protein, $12 \%$ fat, $60 \%$ carbohydrate (14\% disaccharides); LabDiet 5001; PMI Nutrition International). Food and water were provided ad libitum.

\section{Generation of germline G6pc2 KO mice}

The generation of germline G6pc2 $\mathrm{KO}$ mice on a pure C57BL/6J genetic background has been previously described (Wang et al. 2007, Pound et al. 2013). The generation of beta cell-specific (BCS) G6pc2 KO mice is described in the Supplementary material (see section on supplementary materials given at the end of this article).

\section{Mouse and human islet isolation}

Mouse islets were isolated by the Vanderbilt Islet Procurement and Analysis Core as previously described (Syring et al. 2016). Human islets were obtained by A.C.P. through the NIDDK-funded Integrated Islet Distribution Program (https://iidp.coh.org/) and handled and assessed as previously described (Kayton et al. 2015). Human islets designated as 'Group 1' (Kayton et al. 2015) based on islet perifusion analyses (Supplementary Fig. 4) were used for these studies.

\section{Analysis of gene expression}

Tissue RNA was isolated using the ToTALLY RNA kit, whereas islet RNA was isolated using the RNAqueous kit (Ambion, Carlsbad, CA, USA). The Turbo DNA-free DNAse Treatment Kit (Ambion) was then used to remove trace genomic DNA followed by cDNA generation using the iScript DNA Synthesis Kit (Bio-Rad). Gene expression was then quantitated by PCR using the dUTP-containing 
FastStart SYBR Green Master Mix in conjunction with Uracil-DNA-Glycosylase (Roche). Fold induction of gene expression was calculated using the $2(-\Delta \Delta \mathrm{C}(\mathrm{T}))$ method (Livak \& Schmittgen 2001). PCR primer sequences are provided in the Supplementary material.

\section{Phenotypic analysis of fasted germline and BCS G6pc2 KO mice}

Mice were fasted for $5 \mathrm{~h}$ and then weighed. After an additional hour of fasting, mice were anesthetized using isoflurane and blood samples were isolated from the retro-orbital venous plexus. Glucose concentrations were measured in whole blood using a glucose monitor (AccuCheck Advantage; Roche). EDTA (5 $\mu \mathrm{L} ; 0.5 \mathrm{M}$ ) was then added to blood samples prior to isolation of plasma by centrifugation. Insulin samples were assayed using RIA (Morgan \& Lazarow 1963) by the Vanderbilt Hormone Assay and Analytical Services Core.

\section{Hematoxylin, eosin and histochemical analysis of tissue morphology}

Mice were killed at 8 months of age and the pancreata were formalin fixed. Pancreata were then paraffin embedded and sections cut at a depth of $5 \mu \mathrm{m}$, dewaxed and stained in hematoxylin and eosin by the Vanderbilt Translational Pathology Shared Resource. Details on the analysis of pancreatic cryo-sections by immunofluorescence are provided in the Supplementary material.

\section{Electronic health record (EHR)-based analyses of human research subjects}

EHR-based analyses were conducted using data on human subjects in the Vanderbilt University Medical Center (VUMC) BioVU DNA databank. Genotyping data in BioVU is linked to the Synthetic Derivative (SD), a de-identified version of the VUMC EHR repository. Detailed descriptions of program operations, ethical considerations, and continuing oversight and patient engagement have been published (Roden et al. 2008, Pulley et al. 2010). The methods used to perform phenome-wide association studies (PheWAS) have been previously published (Denny et al. 2010, 2013). The methods used to perform laboratory value-wide association studies (LabWAS) are described in the GitHub repository [https://bitbucket.org/juliasealock/ labwas/src/master/]

The BioVU sample was restricted to a European American (EA) population $(n=50,115)$ and an African
American (AA) population $(n=9640)$, based on global genetic ancestry estimated from principal components. We used the PheWAS package in $\mathrm{R}$ to perform 1212 logistic regressions to determine whether any Phecodes (hierarchical clustering of International Classification of Disease (ICD) codes) were significantly associated with our SNPs of interest after adjusting for sex, age (defined for each individual as median age across their medical record) and the top four principal components of ancestry (Denny et al. 2010, 2013). For each phenotype, we required a minimum number of 100 cases for inclusion in the PheWAS. We used the LabWAS package to perform 453 linear regressions to determine whether any laboratory values were associated with SNP genotype. The SNPs tested were common in both EA and AA populations.

\section{Glucose cycling}

Glucose cycling was analyzed as previously described (Wall et al. 2015). Briefly, aliquots of 100 islets were incubated for 24 or $72 \mathrm{~h}$ at $28^{\circ} \mathrm{C}$ in RPMI-1640 medium containing $5 \mathrm{mM}$ or $11 \mathrm{mM}$ glucose in a volume of $175 \mu \mathrm{L}$. Islets were incubated in either naturally labeled glucose or $\left[1,2,3,4,5,6,6-{ }^{2} \mathrm{H}_{7}\right]$ glucose (D7-glucose) (98\% isotopic purity per site; Cambridge Isotope Laboratories, Inc., Andover, MA, USA). Following the 24- or 72-h incubation, islets were resuspended by pipetting and pelleted by centrifugation. The supernatant was retained for GC-MS analysis of glucose concentration and mass isotopomer distribution, with glucose concentration determined through comparison to a standard curve. Glucose cycling and glucose uptake rates were calculated as described previously (Wall et al. 2015).

\section{Glycolysis}

Glycolysis was analyzed as described (Ashcroft et al. 1972, Wang \& Iynedjian 1997, Tamarit-Rodriguez et al. 1998). Briefly, aliquots of $\sim 100 \mathrm{WT}$ and germline $G 6 p c 2 \mathrm{KO}$ islets were incubated for $2 \mathrm{~h}$ at $37^{\circ} \mathrm{C}$ in Krebs bicarbonate buffer containing $5.6 \mathrm{mM}$ glucose spiked with $1 \mu \mathrm{D}$-[5${ }^{3} \mathrm{H}$ ]glucose (Perkin Elmer; $10 \mathrm{Ci} / \mathrm{mmol} ; 1 \mathrm{mCi} / \mathrm{mL}$ ) in a volume of $100 \mu \mathrm{L}$. Following the incubation, islets were pelleted by centrifugation. The supernatant was retained for analysis of ${ }^{3} \mathrm{H}_{2} \mathrm{O}$ generation, whereas DNA content of the cell pellet was measured using the Hoechst reagent (Sigma) as described (Ashcroft et al. 1972).

\section{Statistical analyses}

Mouse data were analyzed either using a Student's $t$-test, two sample assuming equal variance or one-way ANOVA, 
assuming normal distribution and equal variance, as indicated. Post hoc analyses were performed using the Bonferroni correction for multiple comparisons. $P$ values indicating the level of significance are shown in the figure legends. EHR associations were analyzed with logistic and linear regressions using the PheWAS package in $\mathrm{R}$ and the LabWAS package in R. PheWAS and LabWAS results were deemed significant if the $P$ value of the association passed a Bonferroni multiple testing correction to account for 1212 logistic and 453 linear regressions that were performed, respectively.

\section{Results}

\section{G6pc isoforms exhibit tissue specific expression in male mice}

While published data strongly suggest that G6PC2 is active in islets, a major unanswered question is whether it is also active in other tissues. The observation from GTEx data that G6PC2 is expressed at low levels in multiple tissues raises this possibility, though it is important to note that there is currently no evidence for detectable G6PC2 protein expression outside of islets. Whether G6PC2 is functionally active in these tissues is likely to depend in part on its expression relative to other G6PC isoforms. We therefore used real-time PCR to compare the tissue specific expression of mouse G6pc1 (Fig. 1A), G6pc2 (Fig. 1B), and G6pc3 (Fig. 1C), as well as Slc37a4 (Fig. 1D). Of the tissues tested, G6pc2 expression was only detected in pancreas (Fig. 1B). In contrast, G6pc1 was expressed predominantly in liver and kidney (Fig. $1 \mathrm{~A})$, whereas $G 6 p c 3$ expression was detected in all tissues examined (Fig. 1C). Similarly, expression of Slc37a4, which is known to couple with G6PC1 and G6PC3 (Pan et al. 2011), was detected in all tissues examined (Fig. 1D). These real-time PCR data are similar to the results of expression analyses for G6pc1 (Shelly et al. 1993), G6pc2 (Arden et al. 1999), G6pc3 (Boustead et al. 2004) and Slc37a4 (Gerin et al. 1997) performed using Northern blotting. These results may indicate that the pattern of G6pc2 expression differs between mouse and human or, more likely, that this apparent difference simply reflects the increased sensitivity of RNA-Seq versus real-time PCR with the former method being able to detect extremely low expression. For example, RNA-Seq data demonstrate that G6PC2 is expressed in liver at $\sim 0.018 \%$ of the level in islets (Ku et al. 2012), a difference too small to easily detect using real-time PCR. Even if G6pc2 is expressed at trace levels in these non-pancreatic tissues, because both
A

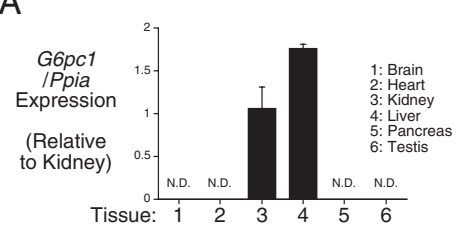

B

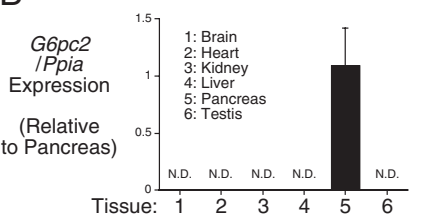

C

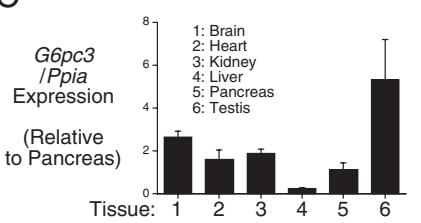

D

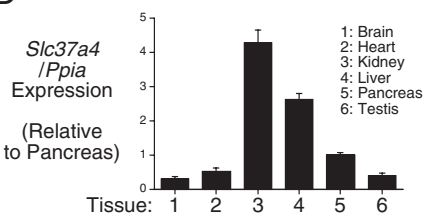

E

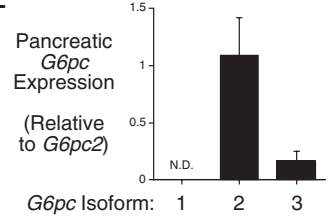

$\mathrm{F}$

G
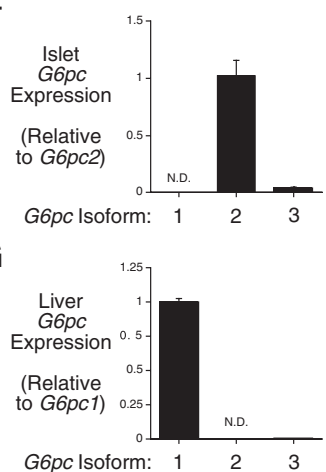

$\mathrm{H}$

\section{Figure 1}

Comparison of tissue-specific G6pc isoform expression in male mice. Comparison of G6pc1 (Panel A), G6pc2 (Panel B), G6pc3 (Panel C) and S/c37a4 (Panel D) expression in brain, heart, kidney, liver, pancreas and testis from 2-month-old non-fasted male mice. G6pc and S/c37a4 expression were quantitated relative to Ppia (cyclophilin A) expression in the indicated tissue and then expressed relative to that in either kidney (Panel A) or pancreas (Panels B, C and D). Comparison of G6pc1, G6pc2 and G6pc3 expression in pancreas (Panel E), islets (Panel F), liver (Panel G) and kidney (Panel H) from 2-month-old non-fasted male mice. G6pc expression was quantitated relative to $G 6 p c 2$ expression in pancreas (Panel E) or islet (Panel F) or relative to G6pc1 expression in liver (Panel G) or kidney (Panel H). Results represent the mean data \pm S.E.M. derived from tissues isolated from three male mice.

G6PC1 (Lei et al. 1993) and G6PC3 (Shieh et al. 2003) have much higher catalytic activity than G6PC2 (Petrolonis et al. 2004), these results suggest that G6PC2 is highly unlikely to directly affect metabolism in these tissues.

\section{The relative expression of G6pc isoforms varies within specific tissues in male mice}

We next examined the relative expression of G6pc isoforms within individual tissues. Within pancreas (Fig. 1E) and islets (Fig. 1F) G6pc2 expression is higher than that of $G 6 p c 3$, and $G 6 p c 1$ expression is not detected. These results suggest that G6PC3 is unlikely to compensate for the absence of G6PC2 in pancreatic islets. Indeed, glucose6-phosphatase activity (Pound et al. 2013) and glucose cycling (Wall et al. 2015) are abolished rather than reduced 
in germline $G 6 p c 2 \mathrm{KO}$ islets. Similarly, G6pc1 expression is higher than that of $G 6 p c 3$ in both liver (Fig. 1G) and kidney (Fig. 1H) suggesting that G6PC3 is unlikely to be able to compensate for the absence of G6PC1 in either tissue, explaining why inactivating mutations in G6PC1 result in glycogen storage disease type 1a despite the presence of G6PC3 (Chou \& Mansfield 2008).

\section{G6pc isoform expression, FBG and FPI change with aging in male mice}

To potentially further establish a critical role for pancreatic G6PC2 in the regulation of FBG, we examined the correlation between the induction of $G 6 p c 2$ expression during development with the ability of G6PC2 to regulate FBG. G6pc2 expression is markedly induced during the weaning period between days 12 and 21 after birth relative to $S l c 2 a 2$, which encodes the GLUT2 glucose transporter (Fig. 2A). Ins2 expression shows a modest induction over this same time period (Fig. 2B). G6pc2 expression changes little between day 21 and day 56 (2 months) (Fig. 2A) and remains unchanged even in old mice (17 months) (Fig. 2C). In contrast, expression of G6pc1 (Fig. 2D) and G6pc3 (Fig. 2E) decline markedly in liver and kidney in old mice. G6pc3 expression remains unchanged in other tissues in old mice (Supplementary Fig. 1) while Slc37a4 expression is selectively reduced in kidney (Fig. 2F). The induction of $G 6 p c 2$ expression at P21 did not correlate with a reduction in FBG in germline $G 6 p c 2 \mathrm{KO}$ relative to WT mice; a reduction was only apparent at P56 (Fig. 2G). Since FBG (Fig. 2G) and especially FPI (Fig. 2H) increase markedly between P21 and P56, we hypothesize that the absence of a difference in FBG between WT and germline G6pc2 KO mice at P21 is simply because the dose response curve for GSIS is at a low point where it is not affected by G6PC2 (Supplementary Fig. 2). A trend toward reduced blood glucose levels is also observed in non-fasted adult G6pc2 KO mice (Fig. 2I), with no change in plasma

\section{A}

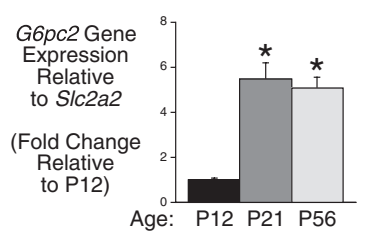

E
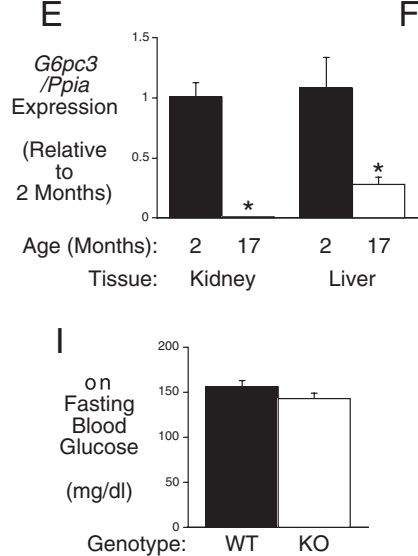

B

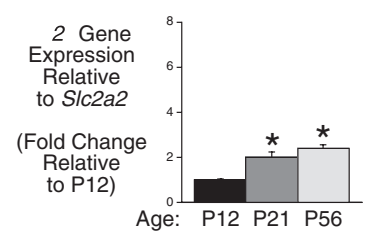

F

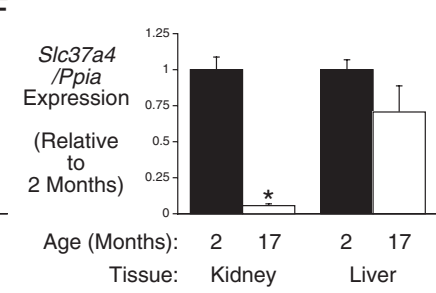

$J$

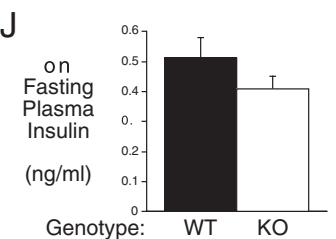

\section{C}

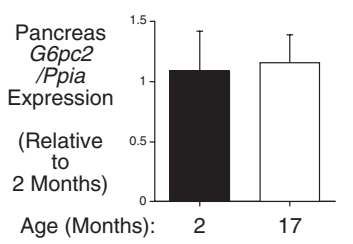

G

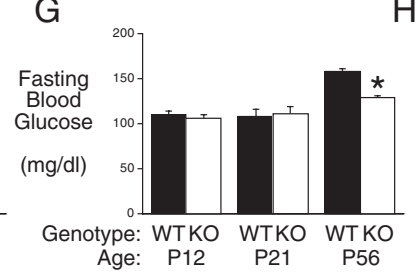

$\mathrm{K}$

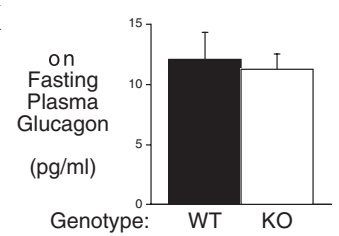

D

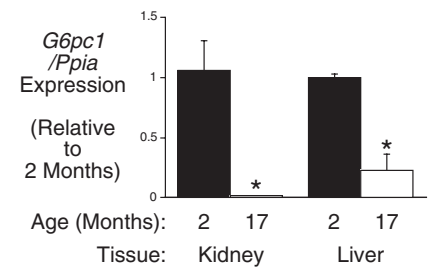

$\mathrm{H}$

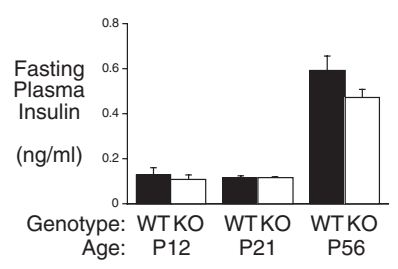

Figure 2

Analysis of changes in G6pc isoform expression, FBG and FPI with aging in male mice. Comparison of pancreatic G6pc2 (Panel A) and Ins2 (Panel B) expression in P12 (non-fasted) and $6 \mathrm{~h}$ fasted P21 and P56 male mice. G6pc2 and Ins2 expression were quantitated relative to S/c2a2 expression and then expressed relative to that at P12. Results represent the mean data \pm S.E.M. derived from pancreata isolated from 3-5 mice. * $P<0.05$ vs P12, one-way ANOVA. Comparison of G6pc2 (Panel C), G6pc1 (Panel D), G6pc3 (Panel E) and Slc37a4 (Panel F) expression in pancreas, kidney or liver in 2- versus 17-month-old non-fasted male mice. G6pc and S/c37a4 expression were quantitated relative to Ppia (cyclophilin A) expression in the indicated tissue and then expressed relative to expression at 2 months. Results represent the mean data \pm S.E.M. derived from tissues isolated from three male mice. $* P<0.05$ vs 2 months. Comparison of FBG (Panel G) and FPI (Panel H) in P12 (non-fasted) and 6-h fasted P21 and P56 male WT and germline G6pc2 KO mice. FBG data represent the mean \pm S.E.M. derived from WT, $n=10 ; \mathrm{KO}, n=7$ (P12), WT, $n=9 ; \mathrm{KO}, n=9$ (P21) and WT, $n=21 ; \mathrm{KO}, n=24$ (P56) mice. FPI data represent the mean \pm S.E.M. derived from WT, $n=10 ; \mathrm{KO}, n=7$ (P12), WT, $n=9$; KO, $n=9$ (P21) and WT, $n=15 ; \mathrm{KO}, n=23$ (P56) mice. * $P<0.05$ vs WT. Comparison of glucose (Panel I), insulin (Panel J) and glucagon (Panel K) in 14-16-week-old non-fasted WT $(n=7)$ and germline G6pc2 KO ( $n=7)$ mice. Data represent the mean \pm S.E.M. 
insulin (Fig. 2J) or glucagon (Fig. 2K). Since the weaning period is associated with the switch to a relatively high carbohydrate diet, we hypothesize that this induction of G6pc2 represents part of the beta cell maturation process (Stolovich-Rain et al. 2015) and is important for enabling the independent offspring to tightly regulate blood glucose levels.

\section{FBG is reduced in male beta cell-specific (BCS) G6pc2 KO mice}

We reasoned that a second approach for addressing whether G6PC2 is also active in other tissues would be through the generation and analysis of beta cell-specific (BCS) G6pc2 KO mice. If the effect of $G 6 p c 2$ deletion on FBG were retained it would argue that G6PC2 primarily regulates FBG through an islet-dependent mechanism. BCS G6pc2 $\mathrm{KO}$ mice were generated by breeding mice with a floxed G6pc2 allele in which LoxP sites surround G6pc2 exon 3, which encodes the third transmembrane domain (Arden et al. 1999), with MIP1-CreERT2 knock in mice in which expression of the CreERT2 recombinase gene is driven by the endogenous mouse insulin1 promoter (Thorens et al. 2015). Treatment of these mice with tamoxifen allows for the removal of exon 3 from the floxed G6pc2 allele in beta cells in adult mice thereby inactivating the gene. Sequence analysis indicates that, were splicing of $G 6 p c 2$ exon 2 to exon 4 to occur, an in-frame G6PC2 variant lacking only exon 3 encoded amino acids would not be generated.

Neither the presence of LoxP sites in the G6pc2 gene nor the presence of the MIP1-CreERT2 gene prior to tamoxifen treatment had major effects on pancreatic G6pc2, Slc37a4 or Ins2 RNA expression in homozygous floxed relative to WT mice (Fig. 3A, B, C, D, E and F). In contrast, tamoxifen treatment (by three days of IP injections) of homozygous floxed mice expressing the MIP1-CreERT2 gene led to a selective $\sim 60 \%$ reduction in pancreatic G6pc2 RNA (Fig. $3 \mathrm{G}, \mathrm{H}$ and $\mathrm{I}$ ) and protein (Fig. $3 \mathrm{~J}$ and $\mathrm{K}$ ) expression in floxed mice relative to WT mice, similar to the efficiency of gene deletion reported by Thorens et al. (2015) using these MIP1-CreERT2 mice.

Neither the presence of LoxP sites in the G6pc2 gene nor the presence of the MIP1-CreERT2 gene prior to tamoxifen treatment affected FBG and FPI (Fig. 4A, B, C and $\mathrm{D})$. In contrast, tamoxifen treatment led to a clear reduction in FBG in floxed mice (Fig. 4E) with no change in FPI (Fig. 4F) indicating that the loss of G6PC2 selectively in beta cells is sufficient to regulate FBG. As expected, the difference in FBG between WT and floxed mice $(\sim 15 \mathrm{mg} /$
dL; WT $n=14$; floxed $n=17$ ) (Fig. 4E) is slightly less than that observed in germline G6pc2 KO mice ( $21 \mathrm{mg} / \mathrm{dL}$; WT $n=31$; KO $n=17$ ) (Pound et al. 2013), consistent with the difference between a partial reduction in G6pc2 expression in BCS G6pc2 KO mice compared to a complete loss of G6pc2 expression in germline $\mathrm{KO}$ mice. These data also suggest that developmental compensation, a common feature in germline $\mathrm{KO}$ mouse studies, has not affected the phenotype of germline G6pc2 KO mice, consistent with the absence of evidence for compensatory changes in pancreatic, islet and liver gene expression comparing WT and G6pc2 KO mice (Supplementary Fig. 3).

\section{Human biobank studies find no evidence for extra-pancreatic actions of G6PC2}

To complement our mouse studies we searched for evidence for potential extra-pancreatic functions of G6PC2 in humans using the Vanderbilt University's Medical Center (VUMC) BioVU Biobank, a DNA biobank linked to a de-identified version of the Vanderbilt electronic health records, called the Synthetic Derivative (SD) (Roden et al. 2008, Pulley et al. 2010). Systematic and efficient approaches have been developed that involve screening the SD with specific SNPs to identify both novel phenotype-variant associations and plasma hormone/metabolite associations, referred to as PheWAS and LabWAS analyses, respectively (Denny et al. 2010, 2011, 2013, Ritchie et al. 2013, Shameer et al. 2014). For these analyses we used the G6PC2 rs560887 SNP that has been shown to affect G6PC2 RNA splicing (Baerenwald et al. 2013) and has been linked by GWAS to variations in FBG (Bouatia-Naji et al. 2008, Chen et al. 2008) and hemoglobin A1c (HbA1c) (Soranzo et al. 2010). PheWAS analyses showed that the G6PC2 rs560887 ' $\mathrm{A}$ ' allele is associated with increased risk for acute pancreatitis in non-diabetic European Americans (EAs) (G6PC2 OR=1.39, $\mathrm{CI}=1.20-1.62, P=2.05 \mathrm{E}-05)$ after Bonferroni correction for the 1212 phenotypes tested (Table 1). Similar, though less statistically significant, trends were observed in the AA sample and in the total (multi-ancestry) population (Table 1). The association with acute pancreatitis was not observed in EAs with type 2 diabetes (T2D) (Table 1) or in African Americans with T2D (AAs; data not shown). Because G6PC2 is not expressed in pancreatic exocrine or ductal tissue (Hutton \& Eisenbarth 2003), this suggests that reduced islet G6PC2 expression can influence non-islet pancreatic tissue function. G6PC2 was not associated with T2D in the total population (Table 1). In contrast, BioVU analyses using the established rs13266634 T2D-associated 
A

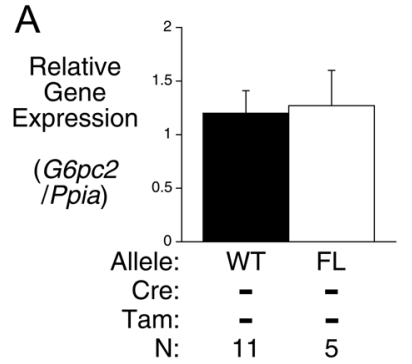

E

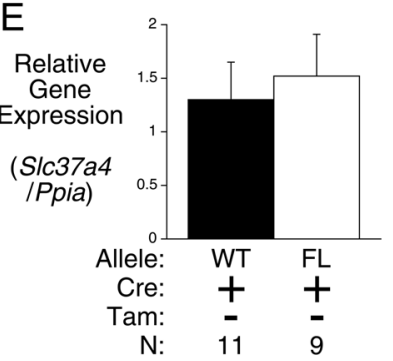

I

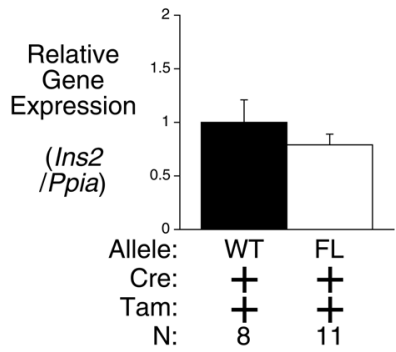

B

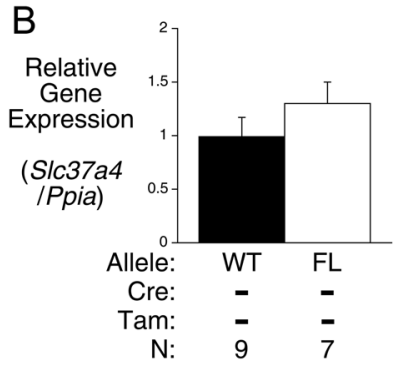

F

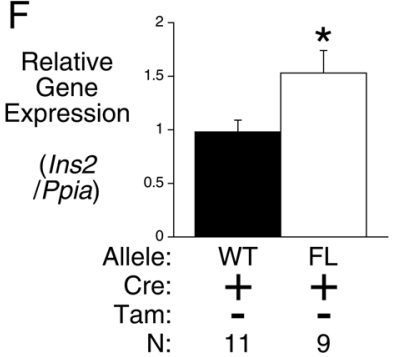

J

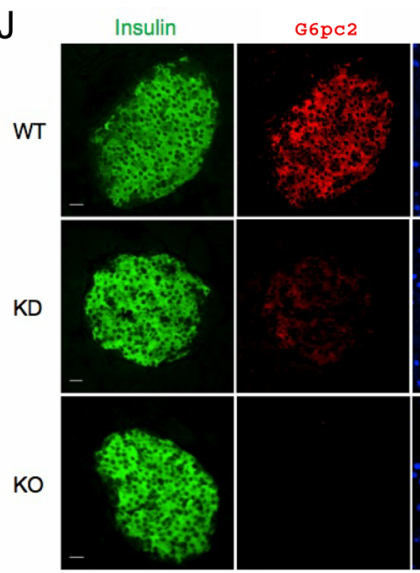

C

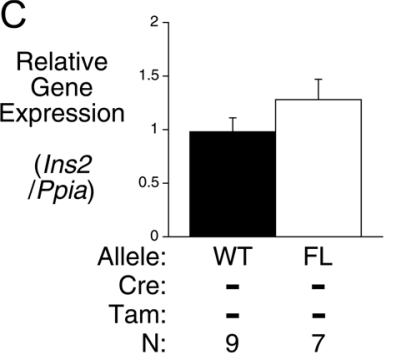

G
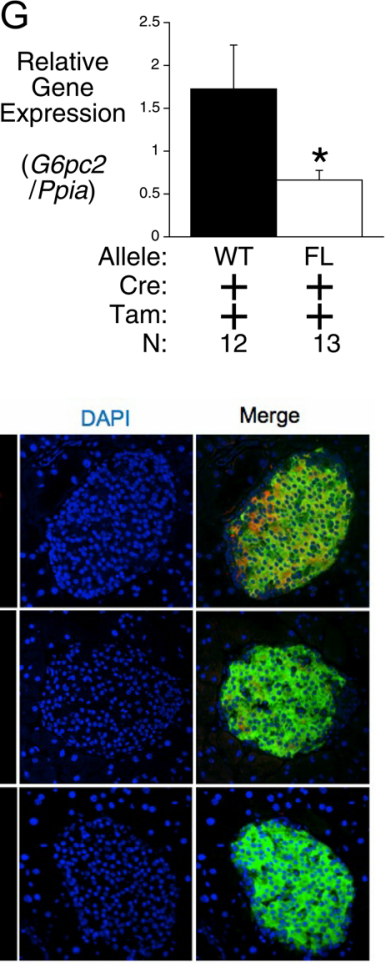

D
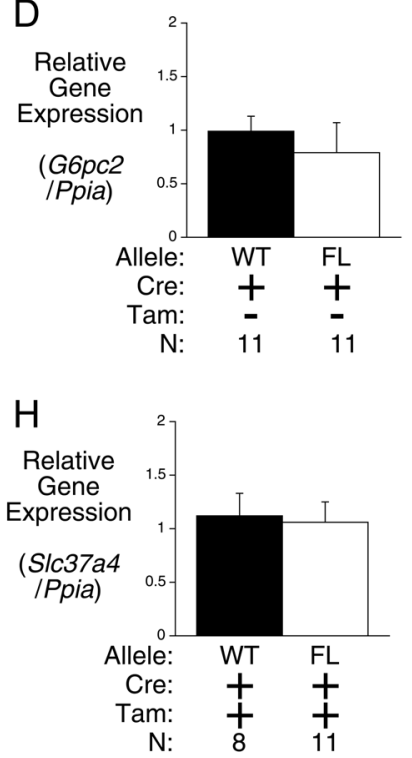

$\mathrm{K}$

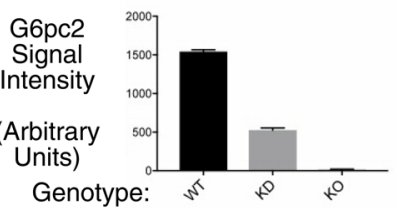

Figure 3

Analysis of G6pc2 RNA and G6PC2 protein expression in floxed G6pc2 male mice. Comparison of pancreatic G6pc2 (Panels A, D and G), S/c37a4 (Panels B, $\mathrm{E}$ and $\mathrm{H}$ ) and Ins2 (Panels C, F and I) expression in 16-week-old 6-h fasted male mice in the presence or absence of the M/P1-CreERT2 allele and in the presence or absence of tamoxifen (Tam) treatment. Pancreatic G6pc2, Ins2 and S/c37a4 expression were quantitated relative to Ppia (cyclophilin A) and then expressed relative to that in WT mice. Results represent the mean data \pm S.E.M. derived from tissues isolated from the indicated number of male mice. Comparison of insulin and G6PC2 protein expression in representative sections of pancreata isolated from WT, germline and BCS G6pc2 KO mice (Panel J). Quantitation of G6PC2 protein expression (Panel K). Data represent the mean \pm s.E.M. from 100 cells for each group. FL, floxed; KD, knockdown. A full colour version of this figure is available at https://doi.org/10.1530/JME-20-0031.

SNP in the SLC30A8 gene (Yaghootkar \& Frayling 2013) did detect an association with T2D (Table 1).

LabWAS analyses showed that the G6PC2 rs560887 'A' allele was associated with reduced blood glucose (Effect estimate $=-0.05$, S.E. $=0.01, P=6.56 \mathrm{E}-24)$ in the total population. Similar trends were observed in the total EA population and in non-diabetic EAs but not EAs with T2D (Table 2) or in AAs (data not shown). Given the differences in sample sizes we cannot rule out the possibility that the lack of association in these groups is simply related to power. The G6PC2 rs560887 'A' allele was also associated with reduced hemoglobin A1c (HbA1c) but only in nondiabetic EAs (Table 2). These results are consistent with GWAS data (Bouatia-Naji et al. 2008, Chen et al. 2008, Soranzo et al. 2010) and suggest that the influence of G6PC2 on blood glucose and HbA1c is lost under diabetic conditions. Surprisingly, the G6PC2 rs560887 'A' allele was associated with increased taurine levels in the total population (effect estimate $=0.32$, s.e. $=0.08, P=7.28 \mathrm{E}-05$ ) with similar trends in the total EA and non-diabetic EA populations (Table 2). It is well established that insulin regulates amino acid metabolism (Rooyackers \& Nair 
A

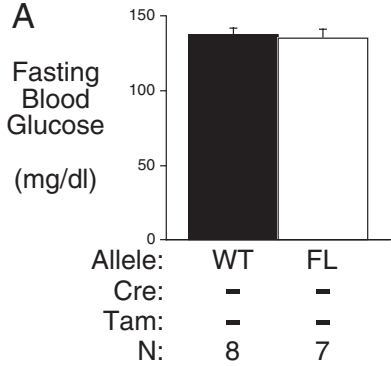

C

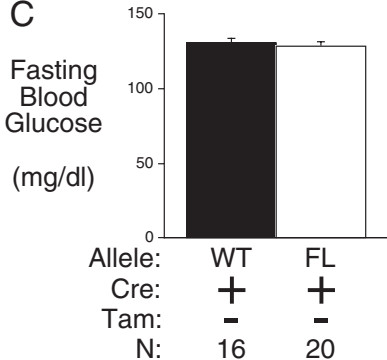

E

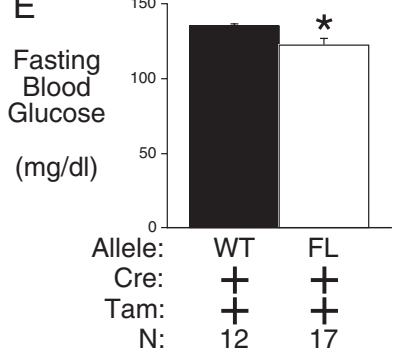

B

Fasting Plasma

Insulin

(ng/ml)

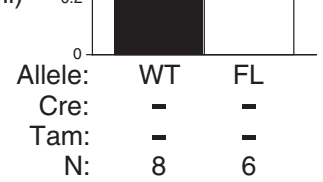

D

Fasting Plasma

Insulin

(ng/ml)
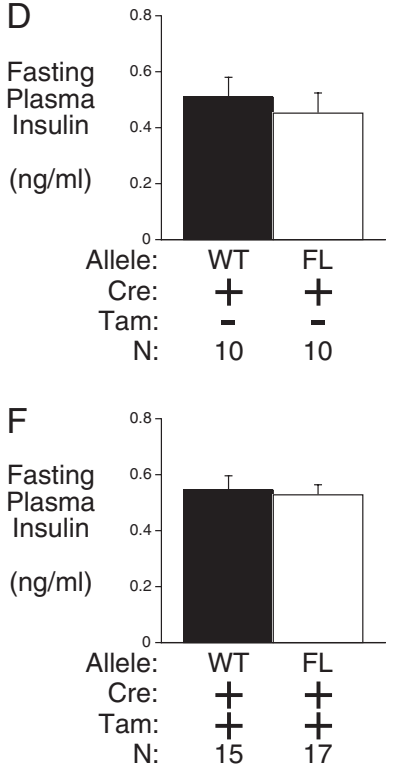

Figure 4

Analysis of FBG and FPI in floxed G6pc2 male mice. Comparison of FBG (Panels A, C and E) and FPI (Panels B, D and F) in 16-week-old 6-h fasted male mice in the presence or absence of the M/P1-CreERT2 allele and in the presence or absence of tamoxifen (Tam) treatment. Results represent the mean data \pm S.E.M. derived from the indicated number of male mice. $\star p<0.05$ vs WT.

1997), so the simplest hypothesis is that reduced islet G6PC2 expression influences the kinetics of insulin secretion which then affects amino acid metabolism. Overall these PheWAS and LabWAS results complement the conclusions of the mouse studies by not finding evidence for extra-pancreatic functions of G6PC2.

To follow-up on these observations from human population studies, we examined whether germline deletion of $G 6 p c 2$ results in pancreatitis in mice. Pancreatic sections from $~ 8$-month-old 6-h fasted mice showed no evidence of pancreatitis, with no necrosis, edema, hemorrhage, steatosis, or fibrosis within the pancreatic parenchyma and no increase in inflammatory infiltrate compared to WT controls. Furthermore, acinar cell morphology appeared normal with no evidence of degranulation, vacuolization, or luminal

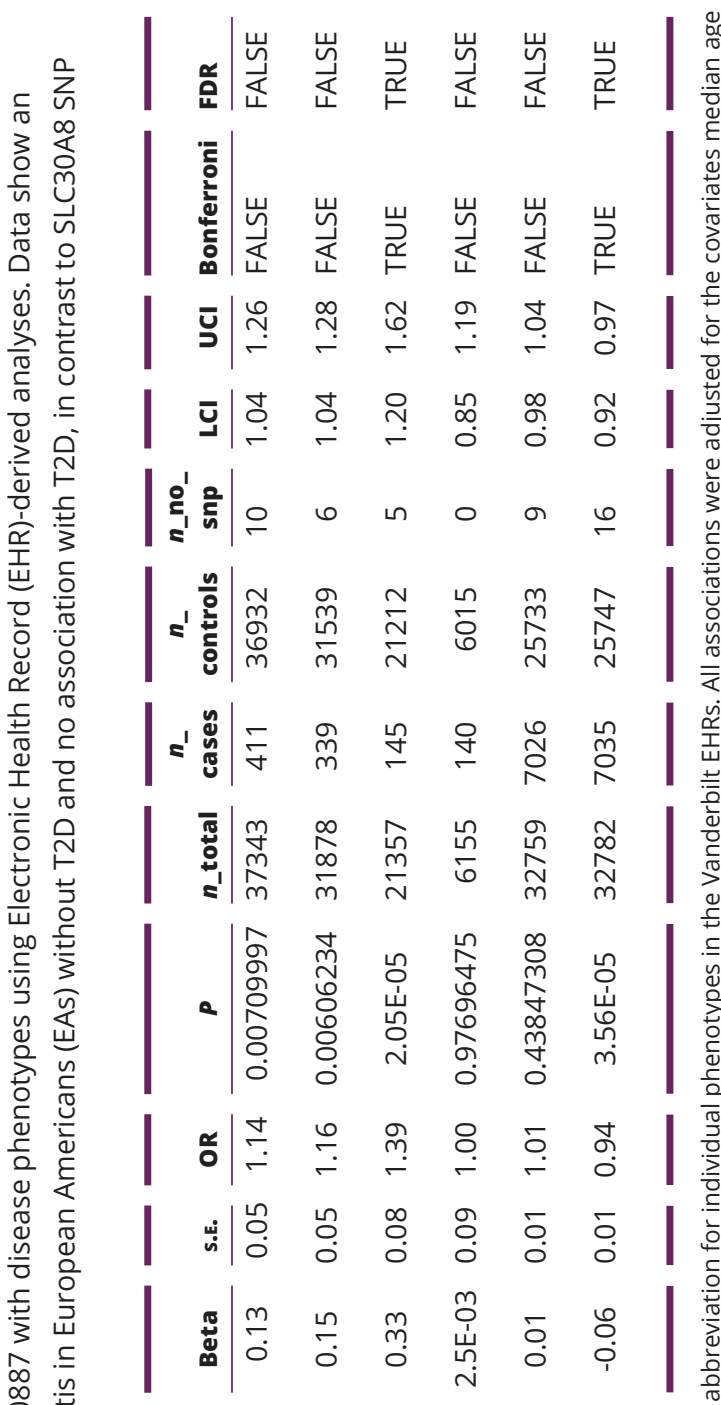




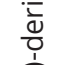

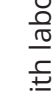

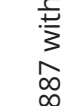

\section{3
$\infty$
$\infty$
$\infty$}

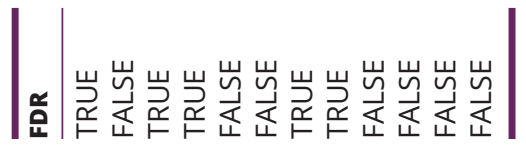

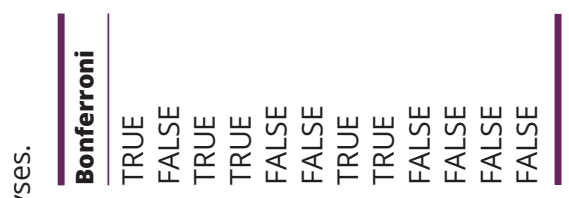

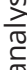

ర্

ฐ

ঊ

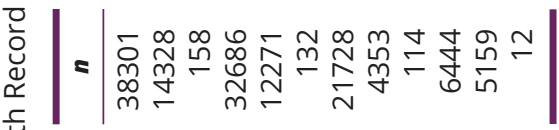

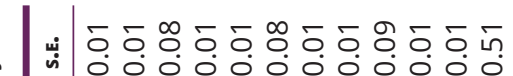
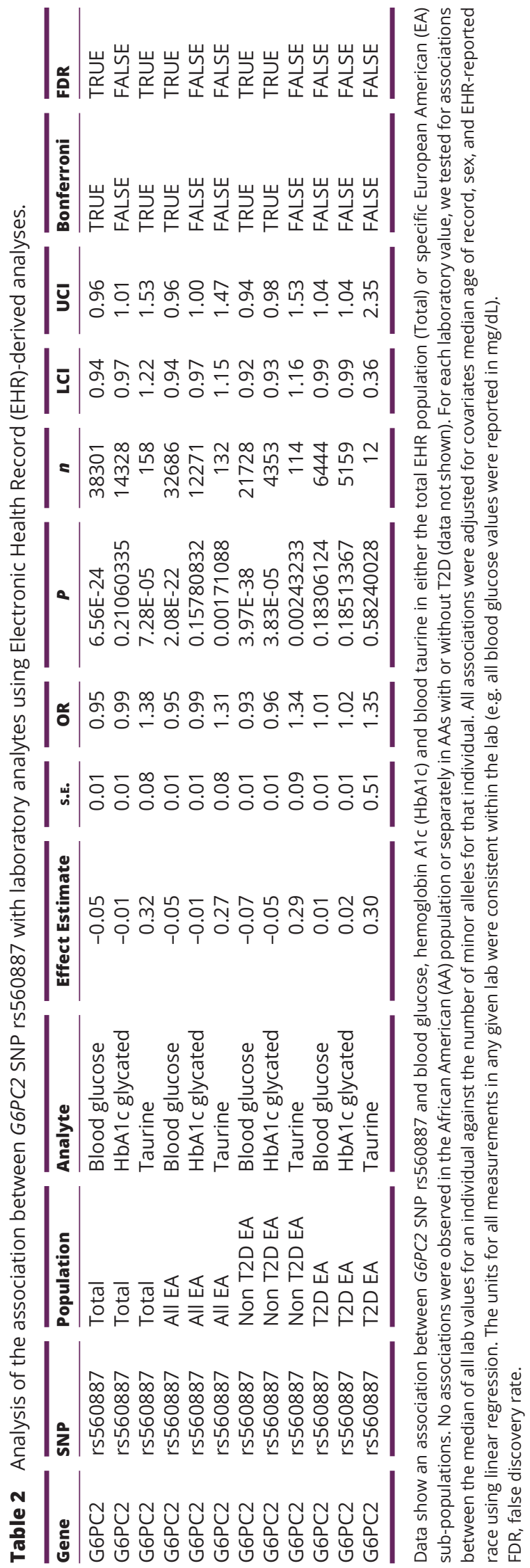

dilation (Fig. 5A). However, expression of Prss1, which encodes trypsinogen, was elevated in 16-week-old 6-h fasted germline G6pc2 KO mice (Fig. 5B). The expression of Ctrb1 (chymotrypsinogen), Amy2a2 (amylase) and Cpa1 (carboxypeptidase A1) were unchanged (Fig. 5B) as were Ins2, Slc30a8 (ZnT8) and Slc37a4, though Slc2a2 expression was slightly reduced (Fig. 5C). Surprisingly the opposite result was observed in 16-week-old 6-h fasted BCS G6pc2 KO mice in which expression of Prss1 was reduced (Fig. 5D).

\section{Glycolysis is enhanced in germline G6pc2 KO relative to WT islets}

Our model predicts that deletion of G6pc2 will increase glycolytic flux in islets. While glucose cycling analyses can quantitate G6P production (Wall et al. 2015) such experiments do not quantitate the rate of glycolysis. It is important to address this key difference because glycolysis, rather than the rate of G6P production, is the determinant of the magnitude of GSIS (Iynedjian 2009, Matschinsky \& Wilson 2019). This distinction arises because G6P has multiple alternate metabolic fates, including conversion to fructose-6-phosphate, glucose1-phosphate, 6-phosphogluconolactone and inositol3-phosphate. The well-established glycolytic assay that measures the generation of ${ }^{3} \mathrm{H}_{2} \mathrm{O}$ from $\mathrm{D}-\left[5^{3} \mathrm{H}\right]$ glucose (Ashcroft et al. 1972, Wang \& Iynedjian 1997, TamaritRodriguez et al. 1998) was used to compare glycolytic rates in WT and germline G6pc2 KO islets. Consistent with our model, glycolysis was elevated in $\mathrm{KO}$ islets at $5.6 \mathrm{mM}$ glucose (Fig. 6).

\section{Glucose cycling exists in human islets}

Using a novel stable isotope-based methodology that eliminates assumptions associated with the use of radioisotopes, we have recently shown that mouse islets exhibit significant rates of glucose cycling (Wall et al. 2015). The same methodology was used to address the key question as to whether glucose cycling also occurs in human islets. Kayton et al. (2015) have recently used islet perifusion assays to define five patterns of GSIS in human islets, designated as Groups $1-5$. Group 1 islets exhibit optimal responses to secretagogues, whereas GSIS shows distinct abnormalities in Groups 2-5 islets (Kayton et al. 2015). Glucose uptake and cycling were compared at both $5 \mathrm{mM}$ and $11 \mathrm{mM}$ glucose in human islet preparations from four donors that were defined as Group 1 using perifusion assays (Supplementary Fig. 4). Significant rates 
B
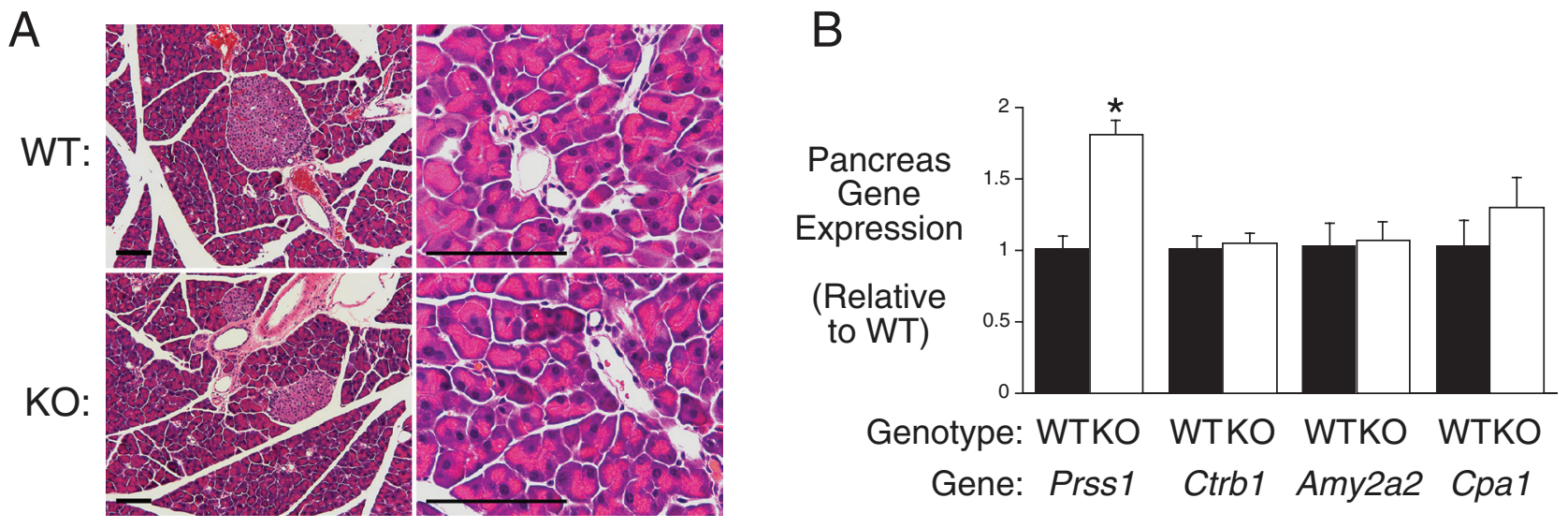

\section{C

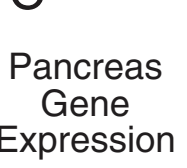

(Relative to WT)

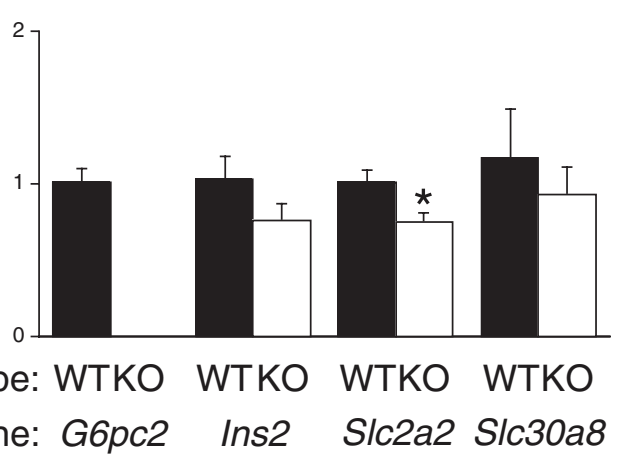

D

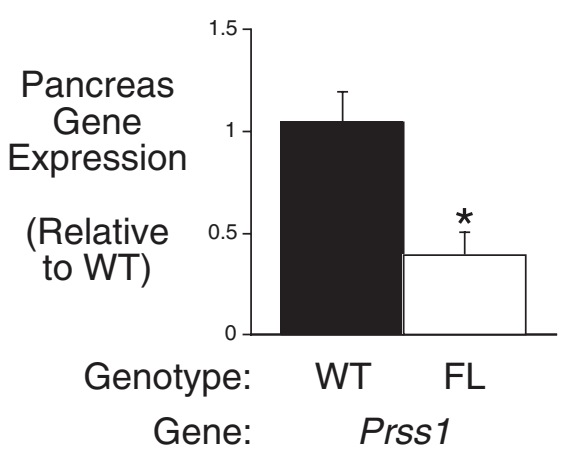

\section{Figure $\mathbf{5}$}

Analysis of pancreatitis and acinar gene expression in germline G6pc2 KO and floxed G6pc2 male mice. (Panel A) Comparison of pancreatic tissue in WT and germline G6pc2 KO mice. Results are representative of sections analyzed from three WT and three KO mice. Size bars represent 100 $\mu \mathrm{m}$. (Panels B and C) Comparison of pancreatic gene expression in 6-h fasted 16-week-old male WT and germline G6pc2 KO mice. Gene expression was quantitated relative to Ppia (cyclophilin A) and then expressed relative to that in WT mice. Results represent the mean data \pm S.E.M. derived from pancreata isolated from five mice. ${ }^{*} P<0.05$ vs WT. (Panel D) Comparison of pancreatic gene expression in 6-h fasted 16-week-old male WT and BCS G6pc2 KO mice following tamoxifen treatment. The RNA samples were a subset of those used in (G), (H) and (I) of Fig. 5. Gene expression was quantitated relative to Ppia (cyclophilin A) and then expressed relative to that in WT mice. Results represent the mean data \pm S.E.M. derived from pancreata isolated from five mice. $\star P<0.05$ vs WT. A full colour version of this figure is available at https://doi.org/10.1530/JME-20-0031.

of glucose uptake and glucose cycling were detected and were typically greater at $11 \mathrm{mM}$ than $5 \mathrm{mM}$ though, for reasons that are unclear, this was not uniform and the islet preparation that exhibited decreased glucose uptake at $11 \mathrm{mM}$ was distinct from the preparation that exhibited decreased glucose cycling at $11 \mathrm{mM}$ (Fig. 7). At $5 \mathrm{mM}$ glucose the level of glucose uptake inversely correlated with the level of glucose cycling (Fig. 7). Since the rate of glucose cycling is determined by quantitating the glucose isotopomers generated by cycling that are transported out of the islets and back into the media, one possible interpretation of this observation is that in cells with high glycolytic flux, re-cycled glucose preferentially re-enters the glycolytic pathway rather than leaving the cell, leading to an underestimate of the rate of cycling. Another possible interpretation is that the rate of G6P dephosphorylation is fairly constant despite changes in glucose uptake, so glucose cycling represents a smaller percentage of glucose uptake when the glucose uptake rate is high. The mean rate of glucose cycling is clearly lower in human (Fig. 7) than mouse (Wall et al. 2015) islets. This correlates with higher basal GSIS (Conrad et al. 2016) and lower G6PC2 expression (Xin et al. 2016) in human versus mouse islets as well as lower FBG in healthy humans (American Diabetes Association 2019) than C57BL/6J mice (Pound et al. 2013).

\section{Discussion}

The experiments described here provide further support for the concept that G6PC2 activity in pancreatic islets creates a glucokinase/G6PC2 futile cycle that determines 


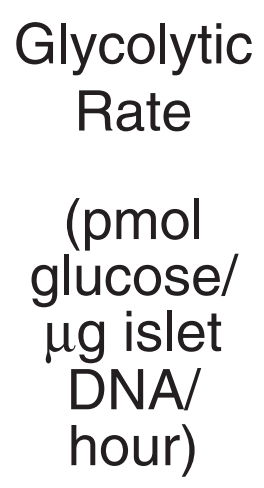

Genotype:

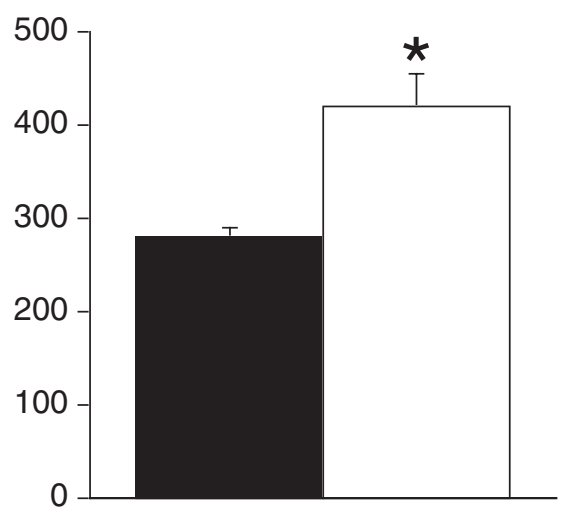

WT KO

\section{Figure 6}

Comparison of glycolytic rates in WT and germline G6pc2 KO islets. Data show the rates of glycolysis in isolated islets from WT and germline G6pc2 $\mathrm{KO}$ mice at $5.6 \mathrm{mM}$ glucose and represent the mean \pm S.E.M.of 5-7 islet samples. ${ }^{*} P<0.05$ vs WT.

the rate of beta cell glycolytic flux and hence the sensitivity of GSIS to glucose rather than this rate being determined by glucokinase alone. Specifically, we show that deletion of G6pc2 enhances glycolysis in mouse islets (Fig. 6) and glucose cycling also exists in human islets (Fig. 7). In addition, gene expression analyses show that G6PC2 is unlikely to be important in non-islet tissues where the more active G6PC isoforms, G6PC1 and G6PC3, are more abundantly expressed (Fig. 1) and that deletion of G6pc2 specifically in beta cells is sufficient to reduce FBG (Figs 3 and 4). Future studies will be designed to confirm that GSIS is enhanced at sub-maximal glucose in perfused pancreata and isolated islets from BCS G6pc2 KO mice as previously observed in germline G6pc2 KO mice (Pound et al. 2013).
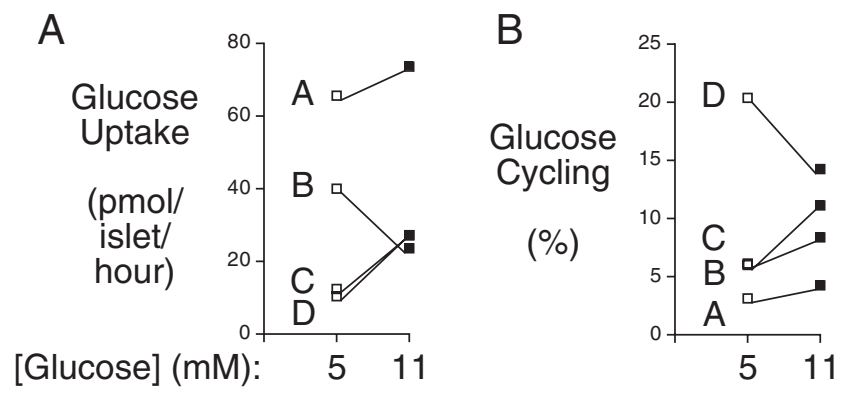

Figure 7

Comparison of glucose uptake and cycling rates in Group 1 human islets. Data show the rates of glucose uptake (Panel A) and cycling (Panel B) in individual preparations of Group 1 islets at either $5 \mathrm{mM}$ or $11 \mathrm{mM}$ glucose from four donors (designated A, B, C and D). Information on the individual human donors is presented in Supplementary Table 1 and information on the insulin secretory profile of each islet preparation, as assessed by islet perifusion, is presented in Supplementary Fig. 4.
Several interesting observations arose from the human biobank studies. First, we observed a strong association between G6PC2 and blood glucose levels (Table 2) even though the BioVU population represents individuals who visit VUMC with a wide range of medical issues and who were not all under overnight fasting conditions when blood was isolated. This suggests that G6PC2 can influence blood glucose under non-fasting conditions, consistent with the concept that altered G6PC2 expression affects the sensitivity of GSIS to glucose over a range of glucose concentrations rather than just at fasting glucose levels (Supplementary Fig. 2). Second, the results show that altered G6PC2 expression in humans can affect the risk of acute pancreatitis (Table 1) and that deletion of G6pc2 in mice alters Prss1 expression (Fig. 5B and D). Since altered Prss1 expression may affect the risk of pancreatitis (Le Marechal et al. 2006, Boulling et al. 2016) this provides a potential mechanistic link between these observations. Since G6PC2 is expressed selectively in pancreatic islet cells (Hutton \& Eisenbarth 2003) the mechanism by which it affects Prss 1 expression and especially why the direction of the effect differs with germline and BCS deletion is unclear but will be the subject of future studies. Finally, we observed that G6PC2 was not associated with altered risk for T2D (Table 1), matching GWAS data that have failed to establish a consistent link with T2D risk (Shi et al. 2017). It will be of considerable interest to identify individuals with mutations that have a major effect on G6PC2 function to determine whether an association with T2D risk then emerges. Elevations in FBG in the prediabetic state correlate with (Brunzell et al. 1976) and appear sufficient to drive (Brereton et al. 2014, Wang et al. 2014) the decline in beta cell function, likely mediated by reactive oxygen species (ROS), that underlies the progression from prediabetes to T2D (Weir \& Bonner-Weir 2004, Halban et al. 2014). However, unless G6PC2 has unknown additional effects on beta cell metabolic flux, a therapy designed to inhibit G6PC2 and thereby lower FBG may fail to prevent this progression because the reduced FBG would be associated with unchanged glycolytic flux and therefore unchanged generation of damaging ROS. Future studies will compare the generation of ROS in WT and $\mathrm{KO}$ islets. While a therapy directed at G6PC2 may not affect T2D risk it would likely still be beneficial in preventing cardiovascular-associated mortality (CAM) in individuals with elevated FBG. Thus, in Europeans, an increase in FBG levels from less than $90 \mathrm{mg} / \mathrm{dL}$ to between 99 and $108 \mathrm{mg} / \mathrm{dL}$ is associated with 30\% increased risk of CAM (Coutinho et al. 1999), and in Asians a reduction in FBG from 99 to $90 \mathrm{mg} / \mathrm{dL}$ is associated with a $25 \%$ 
reduction in the risk of CAM (Lawes et al. 2004). The risk of CAM increases still further in individuals with the high FBG levels characteristic of diabetes (Coutinho et al. 1999, Khaw et al. 2001, DECODE 2003, Lawes et al. 2004).

In mice, $G 6 p c 2$ expression is $\sim 20$ fold higher in beta than alpha cells (Xin et al. 2016), G6PC2 protein is undetectable in alpha cells (Hutton \& Eisenbarth 2003), and glucagon levels are unchanged in germline G6pc2 $\mathrm{KO}$ mice (Wang et al. 2007). The reduction in FBG in germline G6pc2 $\mathrm{KO}$ mice with unchanged FPI is therefore solely due to the shift in the sensitivity of GSIS to glucose, consistent with our glycolysis and BCS G6pc2 KO mouse data. In contrast, in humans G6PC2 expression is only $\sim 5$-fold higher in beta than alpha cells (Xin et al. 2016) such that altered alpha cell glycolysis could contribute to the reduction in FBG in humans with reduced G6PC2 expression.

In summary, these studies show that islet-specific G6PC2 activity is sufficient to regulate FBG, although the possibility that G6PC2 plays some role in tissue-specific metabolism outside the pancreas cannot be excluded.

\section{Supplementary materials}

This is linked to the online version of the paper at https://doi.org/10.1530/ JME-20-0031.

\section{Declaration of interest}

The authors declare that there is no conflict of interest that could be perceived as prejudicing the impartiality of the research reported.

\section{Funding}

This research was supported by the following grants: R O'B, DK92589; O P M, DK043748 and DK078188; A C P, UC4 DK104211, DK106755, DK89572, and by grants from the JDRF and the Department of Veterans Affairs (BX000666); W H L JDRF grant 1-SRA-2018-675-S-B; L K D, R56MH120736; J D Y DK106348. The isolation of mouse islets by the Vanderbilt Islet Procurement and Analysis Core and the measurement of plasma insulin by the Vanderbilt Hormone Assay \& Analytical Services Core were supported by NIH grant P60 DK20593, to the Vanderbilt Diabetes Research Training Center. Human pancreatic islets were provided by the NIDDK-funded Integrated Islet Distribution Program at the City of Hope (NIH Grant \# 2UC4 DK098085). KJ B, S B G, M L W, and K E S were supported by the Vanderbilt Molecular Endocrinology Training Program grant 5T32 DK07563. R O'B is the guarantor of this work, had full access to all the data, and takes full responsibility for the integrity of data and the accuracy of data analysis.

\section{Author contribution statement}

KJ B performed most of the mouse phenotyping studies, gene expression analyses and some of the manuscript writing. M R and $M L W$ performed the human islet glucose cycling studies. K S and S B G performed association studies with EHR data and manuscript editing. J X performed the immunohistochemical studies. K E S performed some of the mouse studies. J K O performed some of the gene expression analyses. G P performed human islet perifusion analyses. O P M contributed to the design of experiments and manuscript editing. LKD contributed to design of EHR studies and manuscript editing. A C P contributed to design of the human islet glucose cycling studies and edited the manuscript. W H L contributed to design of the immunohistochemical studies. J D Y contributed to design of the human islet glucose cycling studies. R M O performed some of the mouse studies and manuscript writing.

\section{Acknowledgements}

The authors thank Susan Hajizadeh, Tracy O'Brien and Brooke Olesnevich for performing insulin, glycogen and glucose cycling assays, respectively. They also thank Joshua C Denny and Huan Mo for their insights on BioVUrelated studies.

\section{References}

American Diabetes Association 2019 2. Classification and diagnosis of diabetes: standards of medical care in Diabetes-2019. Diabetes Care 42 S13-S28. (https://doi.org/10.2337/dc19-S002)

Arden SD, Zahn T, Steegers S, Webb S, Bergman B, O’Brien RM \& Hutton JC 1999 Molecular cloning of a pancreatic islet-specific glucose-6-phosphatase catalytic subunit-related protein. Diabetes $\mathbf{4 8}$ 531-542. (https://doi.org/10.2337/diabetes.48.3.531)

Ashcroft SJ, Weerasinghe LC, Bassett JM \& Randle PJ 1972 The pentose cycle and insulin release in mouse pancreatic islets. Biochemical Journal 126 525-532. (https://doi.org/10.1042/bj1260525)

Baerenwald DA, Bonnefond A, Bouatia-Naji N, Flemming BP, Umunakwe OC, Oeser JK, Pound LD, Conley NL, Cauchi S, Lobbens S, et al. 2013 Multiple functional polymorphisms in the G6PC2 gene contribute to the association with higher fasting plasma glucose levels. Diabetologia 56 1306-1316. (https://doi.org/10.1007/ s00125-013-2875-3)

Bouatia-Naji N, Rocheleau G, Van Lommel L, Lemaire K, Schuit F, Cavalcanti-Proenca C, Marchand M, Hartikainen AL, Sovio U, De Graeve F, et al. 2008 A polymorphism within the G6PC2 gene is associated with fasting plasma glucose levels. Science 320 1085-1088. (https://doi.org/10.1126/science.1156849)

Boulling A, Abrantes A, Masson E, Cooper DN, Robaszkiewicz M, Chen JM \& Ferec C 2016 Discovery and functional annotation of PRSS1 promoter variants in chronic pancreatitis. Human Mutation 37 1149-1152. (https://doi.org/10.1002/humu.23053)

Boustead JN, Martin CC, Oeser JK, Svitek CA, Hunter SI, Hutton JC \& O'Brien RM 2004 Identification and characterization of a cDNA and the gene encoding the mouse ubiquitously expressed glucose-6phosphatase catalytic subunit-related protein. Journal of Molecular Endocrinology 32 33-53. (https://doi.org/10.1677/jme.0.0320033)

Brereton MF, Iberl M, Shimomura K, Zhang Q, Adriaenssens AE, Proks P, Spiliotis II, Dace W, Mattis KK, Ramracheya R, et al. 2014 Reversible changes in pancreatic islet structure and function produced by elevated blood glucose. Nature Communications 5 4639. (https://doi. org/10.1038/ncomms5639)

Brunzell JD, Robertson RP, Lerner RL, Hazzard WR, Ensinck JW, Bierman EL \& Porte Jr D 1976 Relationships between fasting plasma glucose levels and insulin secretion during intravenous glucose tolerance tests. Journal of Clinical Endocrinology and Metabolism $\mathbf{4 2}$ 222-229. (https://doi.org/10.1210/jcem-42-2-222)

Chen WM, Erdos MR, Jackson AU, Saxena R, Sanna S, Silver KD, Timpson NJ, Hansen T, Orru M, Grazia Piras M, et al. 2008 Variations in the G6PC2/ABCB11 genomic region are associated with fasting glucose levels. Journal of Clinical Investigation 118 2620-2628. (https://doi.org/10.1172/JCI34566)

Chou JY \& Mansfield BC 2008 Mutations in the glucose-6-phosphatasealpha (G6PC) gene that cause type Ia glycogen storage disease. Human Mutation 29 921-930. (https://doi.org/10.1002/humu.20772) 
Conrad E, Dai C, Spaeth J, Guo M, Cyphert HA, Scoville D, Carroll J, Yu WM, Goodrich LV, Harlan DM, et al. 2016 The MAFB transcription factor impacts islet alpha-cell function in rodents and represents a unique signature of primate islet beta-cells. American Journal of Physiology: Endocrinology and Metabolism 310 E91-E102. (https://doi.org/10.1152/ajpendo.00285.2015)

Coutinho M, Gerstein HC, Wang Y \& Yusuf S 1999 The relationship between glucose and incident cardiovascular events. A metaregression analysis of published data from 20 studies of 95,783 individuals followed for 12.4 years. Diabetes Care 22 233-240. (https://doi.org/10.2337/diacare.22.2.233)

DECODE 2003 Is the current definition for diabetes relevant to mortality risk from all causes and cardiovascular and noncardiovascular diseases? Diabetes Care 26 688-696. (https://doi. org/10.2337/diacare.26.3.688)

Denny JC, Ritchie MD, Basford MA, Pulley JM, Bastarache L, BrownGentry K, Wang D, Masys DR, Roden DM \& Crawford DC 2010 PheWAS: demonstrating the feasibility of a phenome-wide scan to discover gene-disease associations. Bioinformatics 26 1205-1210. (https://doi.org/10.1093/bioinformatics/btq126)

Denny JC, Crawford DC, Ritchie MD, Bielinski SJ, Basford MA, Bradford Y, Chai HS, Bastarache L, Zuvich R, Peissig P, et al. 2011 Variants near FOXE1 are associated with hypothyroidism and other thyroid conditions: using electronic medical records for genomeand phenome-wide studies. American Journal of Human Genetics 89 529-542. (https://doi.org/10.1016/j.ajhg.2011.09.008)

Denny JC, Bastarache L, Ritchie MD, Carroll RJ, Zink R, Mosley JD, Field JR, Pulley JM, Ramirez AH, Bowton E, et al. 2013 Systematic comparison of phenome-wide association study of electronic medical record data and genome-wide association study data. Nature Biotechnology 31 1102-1110. (https://doi.org/10.1038/ nbt.2749)

Gerin I, Veiga-da-Cunha M, Achouri Y, Collet JF \& Van Schaftingen E 1997 Sequence of a putative glucose 6-phosphate translocase, mutated in glycogen storage disease type Ib. FEBS Letters 419 235-238. (https://doi.org/10.1016/s0014-5793(97)01463-4)

Halban PA, Polonsky KS, Bowden DW, Hawkins MA, Ling C, Mather KJ, Powers AC, Rhodes CJ, Sussel L \& Weir GC 2014 beta-Cell failure in type 2 diabetes: postulated mechanisms and prospects for prevention and treatment. Diabetes Care 37 1751-1758. (https://doi.org/10.2337/ dc14-0396)

Hutton JC \& Eisenbarth GS 2003 A pancreatic beta-cell-specific homolog of glucose-6-phosphatase emerges as a major target of cell-mediated autoimmunity in diabetes. PNAS 100 8626-8628. (https://doi. org/10.1073/pnas.1633447100)

Hutton JC \& O'Brien RM 2009 Glucose-6-phosphatase catalytic subunit gene family. Journal of Biological Chemistry 284 29241-29245. (https://doi.org/10.1074/jbc.R109.025544)

Iynedjian PB 2009 Molecular physiology of mammalian glucokinase. Cellular and Molecular Life Sciences 66 27-42. (https://doi. org/10.1007/s00018-008-8322-9)

Kayton NS, Poffenberger G, Henske J, Dai C, Thompson C, Aramandla R, Shostak A, Nicholson W, Brissova M, Bush WS, et al. 2015 Human islet preparations distributed for research exhibit a variety of insulin secretory profiles. American Journal of Physiology: Endocrinology and Metabolism 308 E592-E602. (https://doi. org/10.1152/ajpendo.00437.2014)

Khaw KT, Wareham N, Luben R, Bingham S, Oakes S, Welch A \& Day N 2001 Glycated haemoglobin, diabetes, and mortality in men in Norfolk cohort of European prospective investigation of cancer and nutrition (EPIC-Norfolk). BMJ 322 15-18. (https://doi.org/10.1136/ bmj.322.7277.15)

Ku GM, Kim H, Vaughn IW, Hangauer MJ, Myung Oh C, German MS \& McManus MT 2012 Research resource: RNA-Seq reveals unique features of the pancreatic beta-cell transcriptome. Molecular Endocrinology 26 1783-1792. (https://doi.org/10.1210/me.2012-1176)
Lawes CM, Parag V, Bennett DA, Suh I, Lam TH, Whitlock G, Barzi F, Woodward M \& Asia Pacific Cohort Studies Collaboration 2004 Blood glucose and risk of cardiovascular disease in the Asia Pacific region. Diabetes Care 27 2836-2842. (https://doi.org/10.2337/ diacare.27.12.2836)

Le Marechal C, Masson E, Chen JM, Morel F, Ruszniewski P, Levy P \& Ferec C 2006 Hereditary pancreatitis caused by triplication of the trypsinogen locus. Nature Genetics 38 1372-1374. (https://doi. org/10.1038/ng1904)

Lei KJ, Shelly LL, Pan CJ, Sidbury JB \& Chou JY 1993 Mutations in the glucose-6-phosphatase gene that cause glycogen storage disease type 1a. Science 262 580-583. (https://doi.org/10.1126/science.8211187)

Livak KJ \& Schmittgen TD 2001 Analysis of relative gene expression data using real-time quantitative PCR and the 2(-Delta Delta C(T)) Method. Methods 25 402-408. (https://doi.org/10.1006/ meth.2001.1262)

Martin CC, Bischof LJ, Bergman B, Hornbuckle LA, Hilliker C, Frigeri C, Wahl D, Svitek CA, Wong R, Goldman JK, et al. 2001 Cloning and characterization of the human and rat islet-specific glucose-6phosphatase catalytic subunit-related protein (IGRP) genes. Journal of Biological Chemistry 276 25197-25207. (https://doi.org/10.1074/jbc. M101549200)

Matschinsky FM \& Wilson DF 2019 The central role of glucokinase in glucose homeostasis: a perspective 50 years after demonstrating the presence of the enzyme in islets of Langerhans. Frontiers in Physiology 10 148. (https://doi.org/10.3389/fphys.2019.00148)

Morgan CR \& Lazarow AL 1963 Immunoassay of insulin: two antibody system: plasma insulin of normal, subdiabetic, and diabetic rats. Diabetes 12 115-126. (https://doi.org/10.2337/diab.12.2.115)

Pan CJ, Chen SY, Jun HS, Lin SR, Mansfield BC \& Chou JY 2011 SLC37A1 and SLC37A2 are phosphate-linked, glucose-6-phosphate antiporters. PLoS ONE 6 e23157. (https://doi.org/10.1371/journal. pone.0023157)

Petrolonis AJ, Yang Q, Tummino PJ, Fish SM, Prack AE, Jain S, Parsons TF, Li P, Dales NA, Ge L, et al. 2004 Enzymatic characterization of the pancreatic islet-specific glucose-6phosphatase-related protein (IGRP). Journal of Biological Chemistry 279 13976-13983. (https://doi.org/10.1074/jbc.M307756200)

Pound LD, Oeser JK, O'Brien TP, Wang Y, Faulman CJ, Dadi PK, Jacobson DA, Hutton JC, McGuinness OP, Shiota M, et al. 2013 G6PC2: a negative regulator of basal glucose-stimulated insulin secretion. Diabetes 62 1547-1556. (https://doi.org/10.2337/db121067)

Pulley J, Clayton E, Bernard GR, Roden DM \& Masys DR 2010 Principles of human subjects protections applied in an opt-out, de-identified biobank. Clinical and Translational Science 3 42-48. (https://doi. org/10.1111/j.1752-8062.2010.00175.x)

Ritchie MD, Denny JC, Zuvich RL, Crawford DC, Schildcrout JS, Bastarache L, Ramirez AH, Mosley JD, Pulley JM, Basford MA, et al. 2013 Genome- and phenome-wide analyses of cardiac conduction identifies markers of arrhythmia risk. Circulation 127 1377-1385. (https://doi.org/10.1161/CIRCULATIONAHA.112.000604)

Roden DM, Pulley JM, Basford MA, Bernard GR, Clayton EW, Balser JR \& Masys DR 2008 Development of a large-scale de-identified DNA biobank to enable personalized medicine. Clinical Pharmacology and Therapeutics 84 362-369. (https://doi.org/10.1038/ clpt.2008.89)

Rooyackers OE \& Nair KS 1997 Hormonal regulation of human muscle protein metabolism. Annual Review of Nutrition 17 457-485. (https:// doi.org/10.1146/annurev.nutr.17.1.457)

Shameer K, Denny JC, Ding K, Jouni H, Crosslin DR, de Andrade M, Chute CG, Peissig P, Pacheco JA, Li R, et al. 2014 A genome- and phenome-wide association study to identify genetic variants influencing platelet count and volume and their pleiotropic effects. Human Genetics 133 95-109. (https://doi.org/10.1007/s00439-0131355-7) 
Shelly LL, Lei KJ, Pan CJ, Sakata SF, Ruppert S, Schutz G \& Chou JY 1993 Isolation of the gene for murine glucose-6-phosphatase, the enzyme deficient in glycogen storage disease type 1A. Journal of Biological Chemistry 268 21482-21485.

Shi Y, Li Y, Wang J, Wang C, Fan J, Zhao J, Yin L, Liu X, Zhang D \& Li L 2017 Meta-analyses of the association of G6PC2 allele variants with elevated fasting glucose and type 2 diabetes. PLOS ONE 12 e0181232. (https://doi.org/10.1371/journal.pone.0181232)

Shieh JJ, Pan CJ, Mansfield BC \& Chou JY 2003 A glucose-6-phosphate hydrolase, widely expressed outside the liver, can explain agedependent resolution of hypoglycemia in glycogen storage disease type Ia. Journal of Biological Chemistry 278 47098-47103. (https://doi. org/10.1074/jbc.M309472200)

Soranzo N, Sanna S, Wheeler E, Gieger C, Radke D, Dupuis J, BouatiaNaji N, Langenberg C, Prokopenko I, Stolerman E, et al. 2010 Common variants at ten genomic loci influence hemoglobin A1C levels via glycemic and non-glycemic pathways. Diabetes $\mathbf{5 9}$ 3229-3239. (https://doi.org/10.2337/db10-0502)

Stolovich-Rain M, Enk J, Vikesa J, Nielsen FC, Saada A, Glaser B \& Dor Y 2015 Weaning triggers a maturation step of pancreatic beta cells. Developmental Cell 32 535-545. (https://doi.org/10.1016/j. devcel.2015.01.002)

Syring KE, Boortz KA, Oeser JK, Ustione A, Platt KA, Shadoan MK, McGuinness OP, Piston DW, Powell DR \& O'Brien RM 2016 Combined deletion of Slc30a7 and Slc30a8 unmasks a critical role for ZnT8 in glucose-stimulated insulin secretion. Endocrinology 157 4534-4541. (https://doi.org/10.1210/en.2016-1573)

Tamarit-Rodriguez J, Idahl LA, Gine E, Alcazar O \& Sehlin J 1998 Lactate production in pancreatic islets. Diabetes 47 1219-1223. (https://doi. org/10.2337/diab.47.8.1219)

Thorens B, Tarussio D, Maestro MA, Rovira M, Heikkilä E \& Ferrer J 2015 Ins1(Cre) knock-in mice for beta cell-specific gene recombination. Diabetologia 58 558-565. (https://doi.org/10.1007/s00125-0143468-5)
Veiga-da-Cunha M, Chevalier N, Stephenne X, Defour JP, Paczia N, Ferster A, Achouri Y, Dewulf JP, Linster CL, Bommer GT, et al. 2019 Failure to eliminate a phosphorylated glucose analog leads to neutropenia in patients with G6PT and G6PC3 deficiency. PNAS 116 1241-1250. (https://doi.org/10.1073/pnas.1816143116)

Wall ML, Pound LD, Trenary I, O'Brien RM \& Young JD 2015 Novel stable isotope analyses demonstrate significant rates of glucose cycling in mouse pancreatic islets. Diabetes 64 2129-2137. (https:// doi.org/10.2337/db14-0745)

Wang H \& Iynedjian PB 1997 Modulation of glucose responsiveness of insulinoma beta-cells by graded overexpression of glucokinase. PNAS 94 4372-4377. (https://doi.org/10.1073/pnas.94.9.4372)

Wang Y, Martin CC, Oeser JK, Sarkar S, McGuinness OP, Hutton JC \& O'Brien RM 2007 Deletion of the gene encoding the islet-specific glucose-6-phosphatase catalytic subunit-related protein autoantigen results in a mild metabolic phenotype. Diabetologia 50 774-778. (https://doi.org/10.1007/s00125-006-0564-1)

Wang Z, York NW, Nichols CG \& Remedi MS 2014 Pancreatic beta cell dedifferentiation in diabetes and redifferentiation following insulin therapy. Cell Metabolism 19 872-882. (https://doi.org/10.1016/j. cmet.2014.03.010)

Weir GC \& Bonner-Weir S 2004 Five stages of evolving beta-cell dysfunction during progression to diabetes. Diabetes $\mathbf{5 3}$ (Supplement 3) S16-S21. (https://doi.org/10.2337/diabetes.53. suppl_3.s16)

Xin Y, Kim J, Okamoto H, Ni M, Wei Y, Adler C, Murphy AJ, Yancopoulos GD, Lin C \& Gromada J 2016 RNA sequencing of single human islet cells reveals Type 2 diabetes genes. Cell Metabolism 24 608-615. (https://doi.org/10.1016/j. cmet.2016.08.018)

Yaghootkar H \& Frayling TM 2013 Recent progress in the use of genetics to understand links between type 2 diabetes and related metabolic traits. Genome Biology 14 203. (https://doi.org/10.1186/gb-201314-3-203)

Received in final form 26 February 2020

Accepted 13 march 2020

Accepted Manuscript published online 16 March 2020
(C) 2020 Society for Endocrinology Published by Bioscientifica Ltd. Printed in Great Britain 